\title{
Simulasi Channel Coding Pada Sistem DVB-C (Digital Video Broadcasting-Cable) dengan Kode Reed Solomon
}

\author{
Ruliyanto, Idris Kusuma \\ Program Studi Teknik Elektro, Fakultas Teknik dan Sains, Universitas Nasional Jakarta. \\ Korespondensi: Rully_33@yahoo.co.id
}

\begin{abstract}
ABSTRAK. Digital Video Broadcasting (DVB) adalah salah satu sistem yang digunakan untuk mentransmisikan siaran TV digital hingga ke end-user. Dengan teknologi digital, DVB dapat memanfaatkan penggunaan bandwidth secara lebih efisien. Salah satunya adalah DVB-C (Digital Video Broadcasting-cable). Dalam simulasi ini membandingkan performa antara sistem DVB-C (Digital Video Broadcasting-Cable) tanpa Reed Solomon dengan DVB-C (Digital Video Broadcasting-Cable) yang menggunakan metode Reed Solomon. Hasil penelitian menunjukkan bahwa Reed Solomon mampu memperbaiki kinerja sistem.
\end{abstract}

Keywords: DVB-V, OFDM, Coding, Metode Reed Solomon.

\section{PENDAHULUAN}

Pada saat ini dapat dikatakan bahwa seluruh mata rantai broadcasting mulai dari proses produksi hingga ke distribusi televisi telah dilakukan secara digital, namun mata rantai terakhir proses transmisi ke end-user umumnya masih dilakukan secara analog. DVB (Digital Video Broadcast) adalah salah satu sistem yang digunakan untuk mentransmisikan siaran TV digital hingga ke end-user [1].

Dengan teknologi digital, DVB dapat memanfaatkan penggunaan bandwidth secara lebih efisien. Satu transponder satelit yang biasanya hanya dapat digunakan untuk satu program TV analog, dengan menggunakan DVB dapat digunakan untuk menyiarkan 8 kanal TV digital. Selain penambahan kapasitas kanal TV, pada media transmisi terestrial dapat diperoleh kualitas gambar yang lebih baik dan bahkan pada media kabel TV, DVB-C menawarkan layanan interaksi dua arah [1]

DVB menggunakan dan memiih MPEG-2 untuk kompresi signal audio dan video, karena MPEG-2 mampu mereduksi signal tunggal 166 Mbits menjadi hanya 5 Mbits, sehingga penyelenggara siaran dapat mengirim signal digital menggunakan eksisting media kabel, satelit dan terestrial secara efisien.

\section{LANDASAN TEORI}

DVB (Digital Video Broadcasting) adalah salah satu sistem yang digunakan untuk mentransmisikan siaran TV/Video digital hingga sampai ke pengguna akhir (end-user). DVB dikembangkan berdasarkan latar belakang pentingnya sistem broadcasting yang bersifat terbuka, yang ditunjang oleh kemampuan interoperabilitas, fleksibilitas dan aspek komersial [1].

DVB menawarkan bandwidth secara lebih efisien. Satu transponder satelit yang biasanya hanya dapat digunakan untuk satu program TV analog, dengan menggunakan DVB dapat digunakan untuk menyiarkan 8 kanal TV digital [2]. Selain penambahan kapasitas kanal TV, pada media transmisi terestrial dapat diperoleh kualitas gambar yang lebih baik dan bahkan pada media kabel TV, DVB-C menawarkan layanan interaksi two-way [2].

Salah satu keputusan mendasar yang diambil dalam menetapkan standard DVB adalah pemilihan MPEG-2 sebagai "data containers". Dengan konsepsi tersebut maka transmisi informasi digital dapat dilakukan secara fleksibel tanpa perlu memberikan batasan jenis informasi apa yang akan disimpan dalam "data container" tersebut. Pemilihan MPEG-2 untuk sistem koding dan kompresi dilakukan karena terbukti bahwa MPEG-2 mampu memberikan kualitas yang baik sesuai dengan sumber daya yang tersedia [3] 
Sistem DVB-C yang berpusat pada standar eropa ETSI 300429 yang dibentuk pada tahun 1994 yaitu " sistem saluran digital untuk televisi, suara, dan layanan data, struktur frame, cheannel coding dan modulasi untuk sistem cabel ", dimana untuk kabel jaringan sebagai modulasi paket dengan MPEG-2 melalaui kabel. Standar karakteristiknya sangat baik untuk SNR (signal to noise ratio).

DVB-C merupakan standar konsorsium eropa sebagai transmisi untuk siaran TV digital yang melalui kabel. Sistem transmisinya adalah MPEG-2 atau MPEG-4 yang masih sejenis dengan stream digital audio atau video, dengan menggunakan teknik modulasi QAM dengan channel coding [3].

Salah satu keunggulan dari sebuah sistem komunikasi digital dibandingkan dengan sistem komunikasi analog adalah terletak pada ketahanan sistem tersebut terhadap noise. Sinyal yang terkena noise dapat direkontruksi dengan memanfaatkan threshold dari masing-masing kondisi.

Sedangkan dengan adanya sistem pengkodean, pengaruh noise dari luar terhadap sinyal terkode yang akan ditransmisikan dapat dikurangi begitu pula dengan error yang terjadi dapat dideteksi dan dikoreksi. Channel coding dilakukan untuk menambah performansi bit data yang akan dikirimkan [4].

Kompresi adalah suatu konversi kebalikan dari suatu data ke suatu format yang membutuhkan bit yang lebih sedikit, kompresi dilakukan supaya data disimpan atau dintrasmisikan secara lebih efisien, sehingga ukuran data dalam bentuk terkompresi (compress $C$ ) relatif kecil terhadap ukuran aslinya (Original $\mathrm{O}$ ) dikenal dengan rasio kompresi $(\mathrm{R}=\mathrm{C} / \mathrm{O})$. Jika kebalikan proses yaitu dekompresi, menghasilkan bentuk replika dari data aslinya maka kompresinya adalah lossless.

Lossy compression, biasanya diaplikasikan pada data gambar yang tidak dimungkinkan menghasilkan suatu replika dari gambar aslinya tetapi mempunyai rasio kompresi yang lebih tinggi oleh karena itu lossy compression hanya dimungkinkan dengan suatu pendekatan dari pembangkitan gambar aslinya.

Bit Error Rate adalah parameter yang digunakan untuk mengukur kinerja dari sebuah siste. Dalam penelitian ini digunakan juga BER sebagai indikator penelitian. Pengukurannya dilakukan dengan membandingka jumlah kesalahan dari output dibandingkan dengan jumlah data yang dikirimkan.

\section{PERANCANGAN SIMULASI}

Dalam penelitian ini, blok diagram yang dirancang diberikan pada gambar 1 di bawah ini.

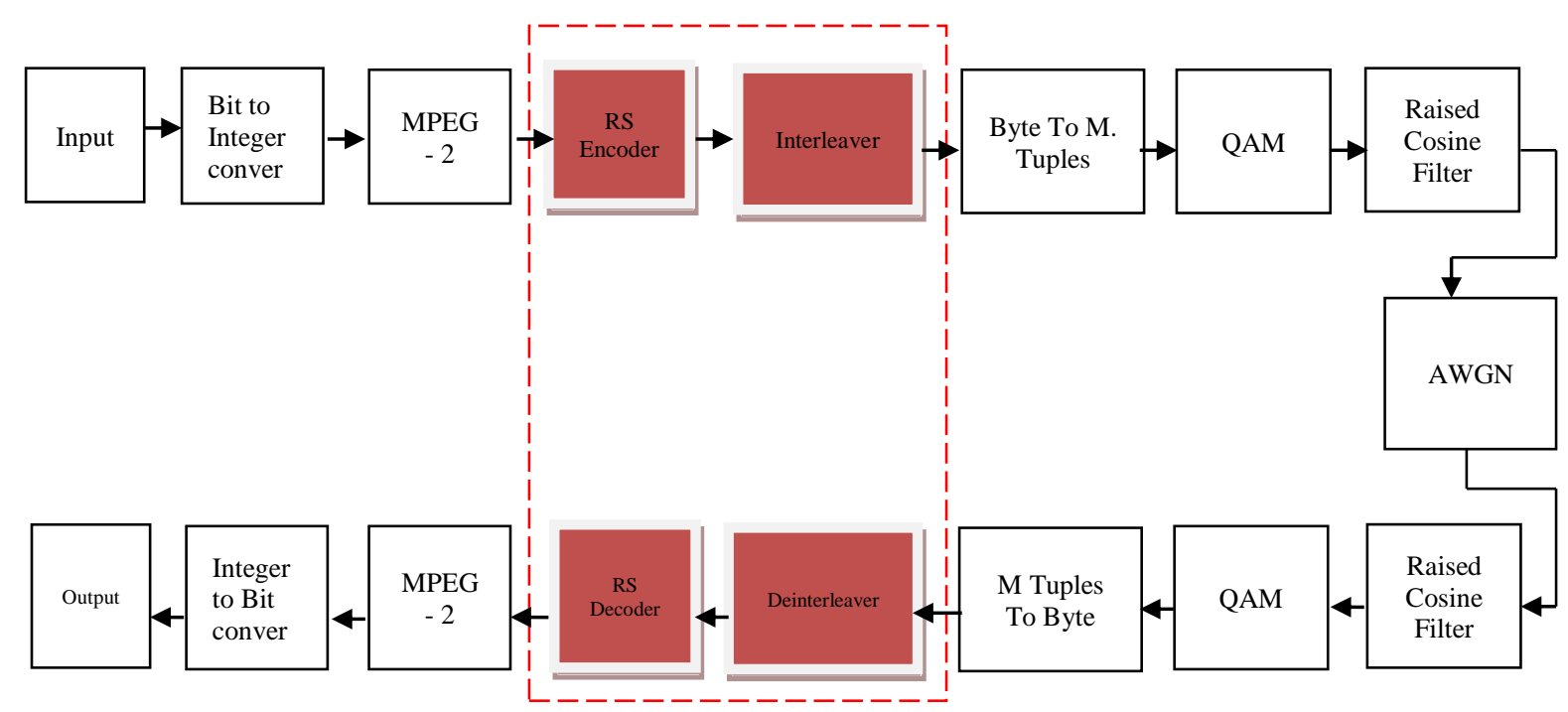

GAMBAR 1. Blok diagram simulasi. 
Dalam penelitian ini, parameter yang digunakan diberikan pada tabel 1.

TABEL 1. Parameter Simulasi.

\begin{tabular}{|l|l|}
\hline \multicolumn{1}{|c|}{ Parameter } & \multicolumn{1}{c|}{ Spesifiksi Parameter } \\
\hline Data Input & $10^{6}$ bit \\
\hline $\mathrm{E}_{\mathrm{b}} / \mathrm{N}_{0}$ & $1-20 \mathrm{~dB}$ \\
\hline mulasiKanal & $A W G N$ \\
\hline Modulasi & $64-\mathrm{QAM}$ \\
\hline M-Arry & $2,4,8,16$, dan 32 \\
\hline Frame Rate & $50 \mathrm{~Hz}$ \\
\hline FEC & Reed Solomon \\
\hline Signal & DVB - C \\
\hline
\end{tabular}

\section{HASIL DAN ANALISA SIMULASI}

Perangkat lunak yang digunakan untuk simlasi adalah program MATLAB. Performa sistem diukur untuk menginfestigasi keluaran hasil rangcangan yang dibuat dalam Bit Error Rate atau BER. Nilai BER ini dihitung berdasarkan nilai SNR yang digunakan. Seperti telah kita ketahui bahwa dengan menggunakan software matlab disertai dengan menyeting parameter-parameter yang mendukung jalannya simulasi maka akan menghasilkan nilai BER (Bit Error Rate) yang sesuai dengan parameter dan input data yang diberikan. Adapun proses simulasi dilakukan dengan memberikan input pada kanal AWGN (Additive White Gaussian Noise) antara $1 \mathrm{~dB}$ sampai $20 \mathrm{~dB}$, seperti pada gambar 2 .
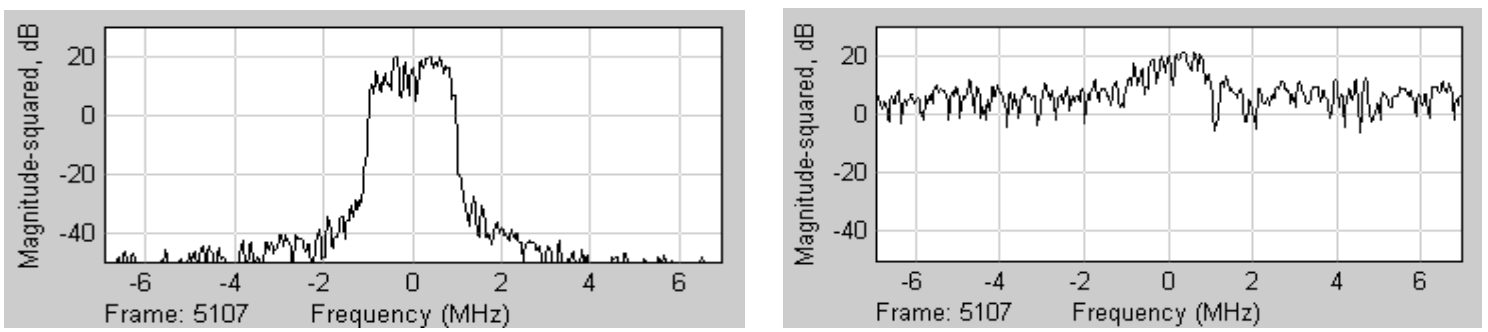

GAMBAR 2. (kiri) Spektrum modulasi pada proses pengiriman data dengan SNR 1 dB, (kanan) Spektrum demodulasi pada saat diterima dengan SNR $1 \mathrm{~dB}$.

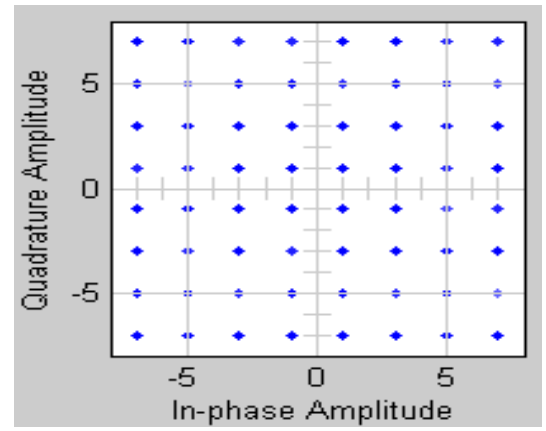

GAMBAR 3. Konstelasi modulasi 64-QAM pada saat pengiriman $1 \mathrm{~dB}$. 


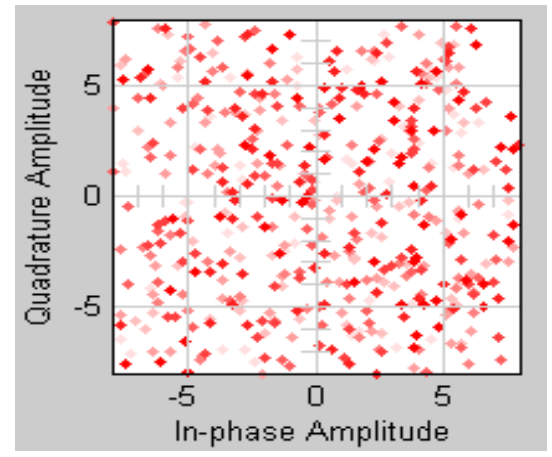

GAMBAR 4. Konstelasi demodulasi 64-QAM pada saat diterima $1 \mathrm{~dB}$.

Pada gambar 2 adalah gambar spektrum simulasi yang memisahkan antara gelombang pembawa dengan gelombang sinyal informasi sebelum dimodulasi. Pada gambar 2 (kanan) adalah gambar spektrum simulasi yang memisahkan antara gelombang pembawa dengan gelombang sinyal informasi setelah mengalami modulasi/demodulasi. Pada gambar 3 dan gambar 4, merupakan konstelasi modulasi dan demodulasi dari sinyal QAM yang digunakan.

\section{HASIL DAN ANALISA SIMULASI}

Hasil simulasi dalam penelitian ini diberikan pada tabel 2 di bawah ini.

TABEL 2. Hasil Penelitian.

\begin{tabular}{|c|l|l|l|l|l|}
\hline Eb/No & $\begin{array}{c}\text { BER } \\
\text { (Dengan reed } \\
\text { Solomon) }\end{array}$ & $\begin{array}{c}\text { BER } \\
\text { (Tanpa Reed } \\
\text { solomo })\end{array}$ & Eb/No & $\begin{array}{c}\text { BER } \\
\text { (Dengan reed } \\
\text { solomon) }\end{array}$ & $\begin{array}{c}\text { BER } \\
\text { (Tanpa Reed } \\
\text { solomon) }\end{array}$ \\
\hline 1 & 0.2129 & 0.2125 & 11 & 0.02006 & 0.02192 \\
\hline 2 & 0.1906 & 0.1902 & 12 & 0.01276 & 0.01276 \\
\hline 3 & 0.1684 & 0.1681 & 13 & 0.003902 & 0.00645 \\
\hline 4 & 0.1472 & 0.1468 & 14 & $5.95 \mathrm{E}-05$ & 0.002825 \\
\hline 5 & 0.1259 & 0.1257 & 15 & 0 & 0.001026 \\
\hline 6 & 0.1053 & 0.105 & 16 & 0 & 0.0002703 \\
\hline 7 & 0.0854 & 0.08512 & 17 & 0 & $6.54 \mathrm{E}-05$ \\
\hline 8 & 0.06641 & 0.06619 & 18 & 0 & $5.77 \mathrm{E}-06$ \\
\hline 9 & 0.04928 & 0.04907 & 19 & 0 & $9.62 \mathrm{E}-07$ \\
\hline 10 & 0.03432 & 0.03415 & 20 & 0 & 0 \\
\hline
\end{tabular}

Dari data dapat diketahui bahwa tanpa menggunakan kode Reed Solomon, maka untuk mencapat minimal BER sebesar $10^{-3}$, maka dibutuhkan (Eb/No.) sebesar $16 \mathrm{~dB}$. Namun demikian dengan penggunaan Reed Solomon, maka sistem hanya membutuhkan daya sebesar $14 \mathrm{~dB}$ saja. Dari data di atas, maka akan dapat dibuat suatu grafik sebagaimana ditunjukkan pada gambar 5 .

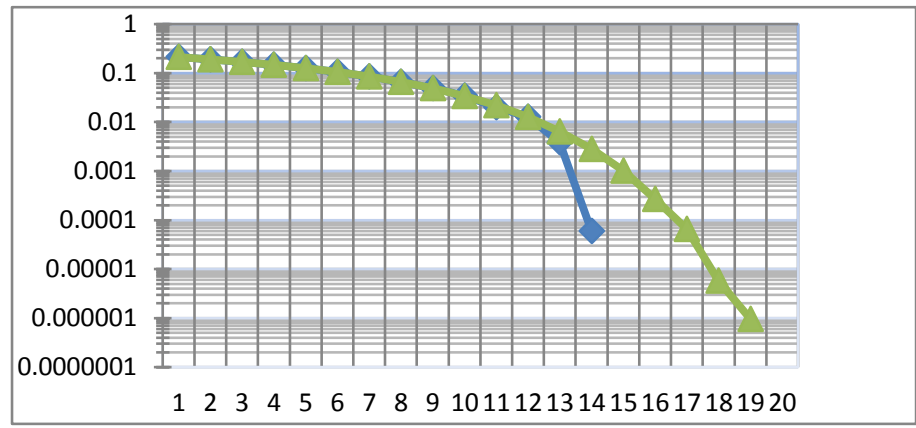

GAMBAR 5. Hasil simulasi. 
Pada gambar 5 dan tabel 2 menunjukan kinerja dari sistem DVB-C yang didapat pada saat melakukan simulasi sehingga nilai yang didapat sangat dipengaruhi oleh besar kecilnya energi bit per noise (Eb/No) yang kita berikan, semakin besar energi yang kita berikan maka akan kecil kemungkinan kesalahan yang terjadi.

Ini terlihat ketika kita berikan input mulai dari $1 \mathrm{~dB}$ sampai $20 \mathrm{~dB}$ dengan menggunakan modulasi 64-QAM terlihat bahwa sistem DVB-C dengan menggunakan metode reed solomon ternyata hasilnya lebih baik yaitu lebih kecil dibawah $10^{-3}$ pada saat diberikan Eb/No nya 14 yaitu dengan nilai 5,95 x $10^{-5}$. Sedangkan pada sistem DVB-C tanpa Reed Solomon bisa mencapai di bawah $10^{-3}$ pada saat Eb/No $17 \mathrm{~dB}$ yaitu dengan nilai $6,54 \times 10^{-5}$. Ini berarti bahwa pada kasus ini Sistem DVB-C lebih baik jika dibanding dengan yang lainya.

\section{KESIMPULAN}

Sistem DVB-C (Digital Video Broadcasting-Cable) dengan menggunakan metode Reed Solomon memberikan performan yang lebih baik bila dibandingkan tanpa menggunakan Reed Solomon.

\section{DAFTAR PUSTAKA}

[1] Yu.Xin Zou "The Design And Analysis Of Increment Services Over Dvb-C Network “ http://www.elektroindonesia.com/elektro

[2] T. Bell, J. Adam, S. Lowe, "Communications", IEEE Spectrum, pp. 30-41,January 1996.

[3] S. Swales, M. Beach, "Third Generation Wireless Networks", University of Bristol, Future Communication Systems course, April 1994.

[4] Sigit Puspito W.J., "Mengenal Teknologi Orthogonal Frequency Division Multiplexing (OFDM) pada Komunikasi Wireless", Elektro Indonesia, Nomor 24, Tahun V, Januari 1999.

[5] Theodore S. Rappaport. "Wirlless comunication: Principles and Practive ". Prentice hall

[6] Zaenal Asiqin " simulasi downlink frekuensi radio satelit geo "skripsi 2007.

[7] Prameswari R. Kusumo1, Sugito2, Indrarini D. I" Analisis Kinerja Mobile Satellite Service (Mss) Pada Frekuensi L-Band Di Indonesia. 